\title{
The Surveillance Outbreak Response Management and Analysis System (SORMAS): Digital Health Global Goods Maturity Assessment
}

Daniel Tom-Aba ${ }^{1,2}$, BScCompSc, MPH; Bernard Chawo Silenou ${ }^{1,2}$, BSc, MSc; Juliane Doerrbecker ${ }^{1}$, MSc, Dr rer nat; Carl Fourie ${ }^{3}$, BScCompSc; Carl Leitner ${ }^{3}$, MPH, PhD; Martin Wahnschaffe ${ }^{4}$, BSc, MSc; Maté Strysewske ${ }^{4}$, BSc, MSc; Chinedu Chukwujekwu Arinze ${ }^{5}$, BSc; Gerard Krause ${ }^{1,2}, \mathrm{MD}, \mathrm{PhD}$

\footnotetext{
${ }^{1}$ Helmholtz Centre for Infection Research, Department of Epidemiology, Braunschweig, Germany

${ }^{2}$ Hannover Medical School (MHH), Hannover, Germany

${ }^{3}$ Digital Square, PATH, Chapel Hill, North Carolina, North Carolina, NC, United States

${ }^{4}$ Symeda GmbH, Braunschweig, Germany

${ }^{5}$ Nigeria Center for Disease Control, Abuja, Nigeria
}

\section{Corresponding Author:}

Daniel Tom-Aba, BScCompSc, MPH

Helmholtz Centre for Infection Research

Department of Epidemiology

Inhoffenstrasse 7

Braunschweig, 38124

Germany

Phone: 4901739136081

Email: daniel.tom-aba@helmholtz-hzi.de

\begin{abstract}
Background: Digital health is a dynamic field that has been generating a large number of tools; many of these tools do not have the level of maturity required to function in a sustainable model. It is in this context that the concept of global goods maturity is gaining importance. Digital Square developed a global good maturity model (GGMM) for digital health tools, which engages the digital health community to identify areas of investment for global goods. The Surveillance Outbreak Response Management and Analysis System (SORMAS) is an open-source mobile and web application software that we developed to enable health workers to notify health departments about new cases of epidemic-prone diseases, detect outbreaks, and simultaneously manage outbreak response.
\end{abstract}

Objective: The objective of this study was to evaluate the maturity of SORMAS using Digital Square's GGMM and to describe the applicability of the GGMM on the use case of SORMAS and identify opportunities for system improvements.

Methods: We evaluated SORMAS using the GGMM version 1.0 indicators to measure its development. SORMAS was scored based on all the GGMM indicator scores. We described how we used the GGMM to guide the development of SORMAS during the study period. GGMM contains 15 subindicators grouped into the following core indicators: (1) global utility, (2) community support, and (3) software maturity.

Results: The assessment of SORMAS through the GGMM from November 2017 to October 2019 resulted in full completion of all subscores $(10 / 30,(33 \%)$ in 2017; 21/30, (70\%) in 2018; and 30/30, (100\%) in 2019). SORMAS reached the full score of the GGMM for digital health software tools by accomplishing all 10 points for each of the 3 indicators on global utility, community support, and software maturity.

Conclusions: To our knowledge, SORMAS is the first electronic health tool for disease surveillance, and also the first outbreak response management tool, that has achieved a $100 \%$ score. Although some conceptual changes would allow for further improvements to the system, the GGMM already has a robust supportive effect on developing software toward global goods maturity. 


\section{KEYWORDS}

mHealth; eHealth; contact tracing; case management; epidemiology; Ebola Virus Disease; West Africa; infectious diseases

\section{Introduction}

\section{Overview}

Digital health is a dynamic field with a rapidly growing number of initiatives and tools, many of which operate in certain geographic areas and for a limited period [1]. This lack of sustainability may be due to a variety of reasons, including the lack of integration in standard frameworks, lack of diverse and continuous donor support, lack of serving the objectives, and limited generalizability of its application among others [2-4]. In the field of public health, funding for such initiatives relies mostly on scarce public resources. Many such parallel initiatives do not seem to be mature enough to survive their pilot phase, which makes it particularly unfortunate. It is in this context that the concept of global goods maturity is gaining importance $[5,6]$.

\section{Global Goods}

The concept of global goods stems from guidelines influencing health policies to support technologies that are meant to assist government agencies and policy makers in launching, scaling, and sustaining digital health innovations [7]. Different ministries of health convened advisory committees, including members of the digital health ecosystem and new multifaceted enterprises such as the Digital Impact Alliance and Digital Square [7]. These included global agencies, governments, philanthropies, funders, and academics to improve health data through shared investments in global goods and to fast-track the development and scale-up of successful digital health solutions to campaign for improvements in the facilitating environment for digital health $[6,8]$. To address the current lack of donor coordination, the committees created a framework to allow shared investments in specific countries and global goods. Health strengthening through enhancing country information systems would contribute to better decision making and, ultimately, better health [6]. The digital investment principles state that the funding donors within countries who are looking to prioritize their needs to improve the health of populations should align their resources around scalable, sustainable, accessible, interoperable, and evidence-based digital health global goods [6].

\section{Surveillance Outbreak Response Management and Analysis System}

The Surveillance Outbreak Response Management and Analysis System (SORMAS) is an open-source mobile and web application software that we developed to enable health workers to notify health departments about new cases of epidemic-prone diseases, detect outbreaks, and manage outbreak response at the same time. SORMAS is a management process system that supports supervisors to validate cases and control the spread of disease. As a multifunctional software, it can be used for case surveillance, laboratory data management, contact tracing, and disease detection to prevent and manage outbreaks that may occur. SORMAS also uses a bidirectional information exchange synchronizing user requests as well as sending feedback to the different users within the existing surveillance system [9-11].

\section{Digital Square Global Goods Maturity Model}

Digital Square, which is an initiative aimed at coordinating international efforts to develop and broadly share useful, free, and open-source digital tools, included 18 mobile health (mHealth) tools into the database of digital health software referred to as "global goods software" [12,13]. Digital Square developed a global good maturity model (GGMM) for digital health tools, which engages the digital health community to identify areas of investments for global goods [12,13]. We identified the GGMM to be a suitable concept in assessing the maturity of SORMAS for the following reasons: (1) GGMM has a particular focus on health software and on that being used in low-resource settings [12,13], (2) the objectives of GGMM matches well with the mission of SORMAS [12,13], and (3) the scope of most of the tools included in the GGMM guidebook fits that of SORMAS [12,13].

The following key concepts are prevalent throughout the study in determining the maturity of SORMAS according to the GGMM: global utility, community support, and software maturity. The objective of this study was to assess the level of global goods maturity that SORMAS has attained using the GGMM version 1.0.

\section{Methods}

We applied the GGMM version 1.0 on SORMAS from November 2017 until October 2019 to assess the level of global goods maturity that it has attained [13]. The GGMM contains 15 subindicators grouped into the following 3 core indicators: (1) global utility, (2) community support, and (3) software maturity. Each subindicator is divided into 3 possible values from -1 for "low," 0 for "medium," to 1 for "high." Each value contains a definition that is listed in Table 1. Given that the GGMM scoring values range from negative to positive values, we applied the following transformation to allow percentage values for summary scores, as shown in equation (1), where, $\mathrm{MS}=$ maturity score for each core indicator, $\mathrm{Si}=$ vector containing scores of the subindicators, and $i=1, \ldots, 5$ :

$$
\mathrm{MS}=5 *\left[\operatorname{MEAN}\left(\mathrm{S}_{\mathrm{i}}\right)\right]+5(1)
$$


Table 1. Global good maturity model 1.0 guideline of digital intervention tools containing 15 subindicators from global utility, community support, and software maturity global indicators.

$\begin{array}{llcl}\text { Indicator } & \text { Low } & \text { Medium }\end{array}$

\section{Global utility}

Country utilization

Country strategy

Digital health interventions

Source code accessibility

Funding and revenue

Community governance

Software roadmap

\section{Community support} community engagement
Less than two countries or states actively use the tool for use as part of their health information system

Less than two countries or states have included the tool as part of their electronic health (eHealth) strategy or framework

The tool does not meet digital functional requirements (as defined by World Health Organization's [WHO's] Classification of Digital Health Interventions) without significant customization or configuration

Source code not publicly available or not released under an open-source license

At most, two revenue streams exist. Revenue streams are largely dependent on time-bound project implementations

Developer, contributor, and implementer

Less than $10 \%$ of the estimated total of developers, contributors and implementers are on a communication platform

There is no community governance structure in place to direct continued development of the digital health tool

No software roadmap exists, or there is no publicly accessible and routinely maintained platform for new feature requests
At least four countries or states actively use the tool for use as part of their health information system, with at least $20 \%$ of total nation-wide or state-wide target users routinely using product or service as intended

At least four countries or states have included the tool as part of their eHealth strategy or framework

The tool does partially meet digital functional requirements (as defined by WHO's Classification of Digital Health Interventions) without significant customization or configuration

Source code exists on a publicly accessible repository and licensed under an open-source initiative approved license

Multiple revenue streams/funders exist across project implementations

Up to $20 \%$ of the estimated total of developers, contributors, or implementers, including some country representation, are engaged on a communication platform

Some informal processes for community management exist to direct continued development of the digital health tool

There is a publicly accessible and routinely maintained platform for new feature requests. A software roadmap exists describing currently planned and resourced development activities
At least ten countries or states actively use the tool for use as part of their health information system, with at least $30 \%$ of total nation-wide or state-wide target users routinely using product/service as intended

At least ten countries or states have included the tool as part of their eHealth strategy or framework

The tool does fully meet digital functional requirements (as defined by WHO's Classification of Digital Health Interventions) without significant customization or configuration

Source code exists on a publicly accessible repository and licensed under an open-source initiative approved license. The software is structured to allow local customizations and new modules and functionality without requiring forking of main code

Multiple revenue streams and funding mechanisms exist, including at least one that provides for multi-year support of core software development, documentation, and other key artifacts

At least $30 \%$ of estimated total developers, contributors, and implementers are engaged on a communication platform. Community leadership includes representation from countries where the tool is deployed

Formal community structures (eg, leadership, technical advisory group, and community representatives) exist and are practiced with documented roles and responsibilities in a transparent fashion and are used to direct continued development of the digital health tool

New features and functionality are documented as part of a software roadmap as part of a release cycle. There are forums for community members to discuss new feature requests. A clear prioritization process exists and is utilized for the development of new features and functionality as part of a product backlog 


\begin{tabular}{|c|c|c|c|}
\hline Indicator & Low & Medium & High \\
\hline User documentation & No user documentation exists & $\begin{array}{l}\text { Some user documenta- } \\
\text { tion exists (training man- } \\
\text { ual, demo videos) but } \\
\text { only addresses a limited } \\
\text { subset of common func- } \\
\text { tionality }\end{array}$ & $\begin{array}{l}\text { A full suite of user documentation } \\
\text { exists, including training manuals, } \\
\text { web-based courses, tutorials, and im- } \\
\text { plementation guides addressing most } \\
\text { of the common functionality. Docu- } \\
\text { mentation has been released under a } \\
\text { Creative Commons license }\end{array}$ \\
\hline
\end{tabular}

Multilingual support

\section{Software maturity}

Technical documentation

Software productization

Interoperability and data accessibility
Limited or no support in the software for multiple languages. Multilingual documentation/user resources are practically nonexistent

No substantial documentation of the software exists

No documentation available for deployment and configuration

Extract or import data into the system usually requires looking at source code and/or directly accessing database
Software has been internationalized to support multiple languages (though may not have been translated) for primary portions of the user interface. Some user documentation exists in more than one language

Some technical documentation exists of the source code, use cases, and functional requirements

Full documentation available for deployment and configuration. A new implementation does not require the involvement of the core development team

Some application programming interfaces (APIs) are available for accessing and managing data. There are user-facing interfaces to export core data and metadata in the system (eg, in CSV format) for further analysis and data transfer purposes

Role-based authorization exists, if appropriate. Guidance on encrypting all remote access (web interface and APIs) is available to implementers
Software has been translated into multiple languages and fully supports internationalization requirements. There is an easy tool for new translations to be added. Significant parts of user and implementer documentation has been translated into at least one other language

Source code is documented to the point that new adopters can customize and add new functionality with relying on significant help from one of the core developers. Online courses or tutorials are available to address common development and deployment tasks. Core business workflows and functional requirements are fully documented using use cases, user stories, or other equivalent methodology

Software has been packaged for one or more common operating systems or platforms. Software upgrades can largely be achieved without manual intervention. Unit or integration testing is part of the release process

A robust API is available for key data and metadata exchange needs for the primary business domain with functional requirements for the API having been developed in conjunction with appropriate country, regional, and global stakeholders. API endpoints exist for core data and metadata elements that adhere to standards developed by an appropriate Standards Development Organization relevant to the tools business domain. Standards-based API endpoints are used in at least four jurisdictions (eg, countries or states)

No security controls or implementation guidance is in place
Role-based authorization exists, if appropriate. All remote access (web interface and APIs) are encrypted by default using current best practices. An independent security audit of the software has taken place within the last 12 months 


\begin{tabular}{|c|c|c|c|}
\hline Indicator & Low & Medium & High \\
\hline Scalability & $\begin{array}{l}\text { There are no jurisdictions (eg, } \\
\text { country and state) that manage } 10 \% \\
\text { of their "entities" within the tool, } \\
\text { and no performance and load statis- } \\
\text { tics exist }\end{array}$ & $\begin{array}{l}\text { There is at least one juris- } \\
\text { diction (eg, country and } \\
\text { state) deployment for } \\
\text { which } 20 \% \text { of all "enti- } \\
\text { ties" are managed within } \\
\text { the software. There has } \\
\text { been at least one evalua- } \\
\text { tion of software perfor- } \\
\text { mance/load testing }\end{array}$ & $\begin{array}{l}\text { There is at least one jurisdictions (eg, } \\
\text { country, state) deployment for which } \\
30 \% \text { of all "entities" are managed } \\
\text { within the software. Performance and } \\
\text { load testing is a part of routine releas- } \\
\text { es, and results are publicly available }\end{array}$ \\
\hline
\end{tabular}

We put together a GGMM assessment group consisting of a public health expert from the Nigerian Centre for Disease Control, a medical epidemiologist, an international health expert, an information technology specialist and a statistician from the Helmholtz Centre for Infections Research, and 2 software engineers from Symeda, a company for developing health software. This group periodically assessed the completion of SORMAS in the 15 subindicators. Subsequently, the software roadmap and the work plan of SORMAS was reprioritized to dedicate resources to and obtain progress in those subindicators that did not reach a full score. To reduce selection bias, as members of the assessment group were part of the development and deployment of SORMAS, and to reduce the potential partiality resulting from it, we also asked 2 external experts to review the findings made by the assessment group. These external experts had contributed to the development of the GGMM and were not involved in the development of SORMAS.

\section{Results}

In November 2017, SORMAS had migrated from a tabletop pilot version to a real-life deployed open-source software and was deployed in 8 federal states and 33 local government areas (LGAs) during the monkeypox outbreak. From September 2016 until November 2017, SORMAS was piloted in 1 state in 2 LGAs and 85 health facilities [14,15]. By February 2018, SORMAS was deployed in 3 additional federal states (71 LGAs) for meningitis outbreak. In March and April 2018, SORMAS was further deployed in 3 additional states (49 LGAs; 5 health facilities) for the Lassa fever outbreak. As of October 2019, SORMAS has been fully established for all epidemic-prone diseases in 15 federal states (including the federal capital), 287 LGAs, 37 health facilities, and approximately 700 users covering a population of 75 million. SORMAS managed multiple outbreaks simultaneously across the country. The assessment of SORMAS applying the GGMM showed that SORMAS had a 10-point score each in global utility, community support, and software maturity (see Table 2). 
Table 2. The distribution of subindicator mean scores among the 3 core indicators (global utility, community support, and software maturity) for Surveillance Outbreak Response Management and Analysis System development from November 2017 to October 2019.

\begin{tabular}{|c|c|c|c|c|}
\hline \multirow[t]{2}{*}{ Core indicator $^{\mathrm{a}}$} & \multicolumn{3}{|l|}{ Score } & \multirow[t]{2}{*}{ Status of SORMAS ${ }^{b}$} \\
\hline & 2017 & 2018 & 2019 & \\
\hline Global utility & 6 & 9 & 10 & $\mathrm{~N} / \mathrm{A}^{\mathrm{c}}$ \\
\hline Country utilization & 1 & 1 & 1 & $\begin{array}{l}\text { SORMAS has been fully established for all epidemic-prone dis- } \\
\text { eases in } 15 \text { federal states (including the federal capital), } 287 \text { local } \\
\text { government areas, } 37 \text { health facilities, and approximately } 700 \text { users } \\
\text { covering } 75 \text { million population (November 2017) }\end{array}$ \\
\hline Country strategy & 0 & 1 & 1 & $\begin{array}{l}\text { SORMAS has now been fully integrated into the revised technical } \\
\text { guidelines of the Integrated Disease Surveillance and Response } \\
\text { strategy and eHealth framework (September 2019) }\end{array}$ \\
\hline Digital health interventions & -1 & 1 & 1 & $\begin{array}{l}\text { SORMAS can be configured and deployed without significant } \\
\text { customizations or configuration (July 2019) }\end{array}$ \\
\hline Source code accessibility & 0 & 0 & 1 & $\begin{array}{l}\text { SORMAS has an open-source initiative approved license (GNU } \\
\text { General Public License, Version 3, June 29, 2007) and is structured } \\
\text { to allow local customizations and SORMAS is web-based and } \\
\text { provides a relatively clear application programming interface (API) } \\
\text { and database model. So, it is easy to build new modules and func- } \\
\text { tionalities and host it on the same server (August 2019) }\end{array}$ \\
\hline Funding and revenue & 1 & 1 & 1 & $\begin{array}{l}\text { SORMAS is has been funded by the following donors and partners } \\
\text { since its inception; Federal Ministry of Economic Cooperation and } \\
\text { Development and the European Union via Deutsche Gesellschaft } \\
\text { für Internationale Zusammenarbeit, BMBF } \text {, Bill and Melinda } \\
\text { Gates Foundation, Nigerian Basic Health Care Provision Fund, } \\
\text { US Centers for Disease Control and Prevention, Deutschen Zentrum } \\
\text { für Infektionsforschung (DZIF). Funding sources for SORMAS } \\
\text { increased from } 1 \text { in 2017, } 3 \text { in 2018, to } 7 \text { in } 2019 \text { (October 2019) }\end{array}$ \\
\hline Community & 3 & 7 & 10 & N/A \\
\hline $\begin{array}{l}\text { Developer, contributor, and imple- } \\
\text { menter community engagement }\end{array}$ & -1 & 1 & 1 & $\begin{array}{l}\text { SORMAS currently has at least } 30 \% \text { of estimated total developers } \\
\text { from Nigeria, Tanzania, Ghana, and Germany (May 2018) }\end{array}$ \\
\hline Community governance & 1 & 1 & 1 & $\begin{array}{l}\text { In Nigeria, the steering board consists of representatives of } \\
\text { Helmholtz Centre for Infection Research (HZI), Nigeria Centre } \\
\text { for Disease Control, and in Ghana, the steering board includes } \\
\text { Ghana Health Service, Ghana Community Network (GCNET), } \\
\text { and HZI. The steering board is furthermore supported by an inter- } \\
\text { national external advisory board and an open-source clearance } \\
\text { board (January 2018) }\end{array}$ \\
\hline Software roadmap & -1 & 0 & 1 & $\begin{array}{l}\text { New features and functionalities are documented as part of the } \\
\text { SORMAS road map and are also part of a biweekly release cycle } \\
\text { (May 2019) }\end{array}$ \\
\hline User documentation & 0 & 0 & 1 & $\begin{array}{l}\text { SORMAS currently has user guides and technical documentation } \\
\text { in which the source codes, use cases, and functional requirement } \\
\text { exists, including training videos that are available to address every- } \\
\text { day deployment tasks (August 2018) [16] }\end{array}$ \\
\hline Multilingual support & -1 & 0 & 1 & $\begin{array}{l}\text { SORMAS has a multilingual support mechanism for English and } \\
\text { French on its platform. The language translation component in } \\
\text { SORMAS is easy to configure by a non-information technology } \\
\text { (IT) person and can be adapted into any language required } \\
\text { (February 2019) }\end{array}$ \\
\hline Software & 1 & 5 & 10 & N/A \\
\hline Technical documentation & 0 & 0 & 1 & $\begin{array}{l}\text { SORMAS has full documentation for deployment and configura- } \\
\text { tion, which does not require the involvement of the core develop- } \\
\text { ment team. The SORMAS mobile app has only been packaged for } \\
\text { the Android version operation system and not yet packaged for the } \\
\text { iPhone operating system. The SORMAS web app has been pack- } \\
\text { aged for Windows, Apple, and Linux operating systems (August } \\
2018 \text { ) }\end{array}$ \\
\hline
\end{tabular}




\begin{tabular}{|c|c|c|c|c|}
\hline \multirow[t]{2}{*}{ Core indicator $^{\mathrm{a}}$} & \multicolumn{3}{|l|}{ Score } & \multirow[t]{2}{*}{ Status of SORMAS ${ }^{b}$} \\
\hline & 2017 & 2018 & 2019 & \\
\hline Software productization & -1 & 0 & 1 & $\begin{array}{l}\text { SORMAS has automatic software upgrades without the manual } \\
\text { intervention of the developers and also has integrated unit testing } \\
\text { as part of the release process (August 2019) }\end{array}$ \\
\hline $\begin{array}{l}\text { Interoperability and data accessibil- } \\
\text { ity }\end{array}$ & -1 & 0 & 1 & $\begin{array}{l}\text { API end points exist within SORMAS for accessing and managing } \\
\text { data, and SORMAS has user interfaces to export core data and } \\
\text { metadata in the system (CSV format) for further analysis and data } \\
\text { transfer purposes (August 2017) }\end{array}$ \\
\hline Security & -1 & 0 & 1 & $\begin{array}{l}\text { Role-based authorization exists within SORMAS and all remote } \\
\text { access via the web interface and APIs are encrypted by default. } \\
\text { SORMAS has undergone an independent security audit of the } \\
\text { software, which has taken place within the past } 12 \text { months (May } \\
\text { 2019) }\end{array}$ \\
\hline Scalability & -1 & 0 & 1 & $\begin{array}{l}\text { We have deployed SORMAS in at least } 30 \% \text { of all entities, which } \\
\text { are managed within the software. There has been a surge in the } \\
\text { number of users and deployments across the country in the last } \\
\text { year (Indicator } 2 \text {, subindicators J criteria). For every SORMAS } \\
\text { release, we evaluate the software performance and perform load } \\
\text { testing and IT integrated testing (October 2019) }\end{array}$ \\
\hline Total score, n (\%) & $10(33)$ & $21(70)$ & $30(100)$ & N/A \\
\hline
\end{tabular}

aThe global good maturity model assigned scores for each subindicator as -1 for "low," 0 for "medium," and 1 for "high," and computed average values for the 5 subindicators of each core indicator using the formula in equation (1) MS=5*[MEAN (Si) $]+5$, where, MS=Maturity score for each core indicator $\mathrm{S}, \mathrm{i}=$ subindicator, $\mathrm{i}=1, \ldots, 5$ (vector containing score of the subindicators).

${ }^{\mathrm{b}}$ SORMAS: Surveillance Outbreak Response Management and Analysis System.

${ }^{\mathrm{c}}$ N/A: not applicable.

${ }^{d}$ BMBF: German Federal Ministry of Education and Research

\section{Discussion}

\section{Principal Findings}

SORMAS has reached the full score of the GGMM. The process from the decision to migrate a prototype based on a Systems, Applications, and Products proprietary technology stack to open-source software in 2016 until the accomplishment of the full score lasted 3 years [10]. There is no registry or publicly available documentation of tools that have applied the GGMM assessment except the District Health Information System 2 [17]. Of all the mHealth tools selected as global goods software listed in the GGMM guidebook, none have accomplished over $90 \%$ of the full score nor are we aware of any other tool that has obtained it [13]. Thus, it appears very likely that SORMAS may be the first and, so far, only digital tool that has reached the full score of the GGMM. SORMAS has multiple revenue streams and funding mechanisms that have been enabling progress in its development since 2016. SORMAS requires funding for software adaptations to country-specific requests, personnel for training, and supervision and maintenance of the tool.

The outline and the scoring principle of the GGMM version 1.0 was easy to apply. However, there were some limitations concerning the clarity of the definition of each of the 3 possible criteria of the subindicators. Many of those definitions contained a combination of several contextually independent items, for which the wording did not clearly distinguish between "AND" or "OR" combinations. Some definitions left room for interpretation, which may be necessary for some but also be too ambiguous in other situations. The 30 subindicators grouped into 3 core indicators all have equal weights keeping the model and its handling simple.

On the other hand, it may also not represent the difference in importance that different indicators may have. For example, it may be considered essential for global goods maturity to have repetitive external security tests implemented than multilinguarity. Once the full score has been accomplished, these differences are no longer relevant. However, as long as the total score is only partially completed, the quantitative value may be very misleading in the attempt to compare tools. A way to improve this dilemma would be to add weights to each indicator. A more natural way would be to discourage the computation of proportional completion and to categorically apply a dichotomous all-or-nothing principle, by which all requirements have been either fully fulfilled or not fulfilled [18]. Some indicators address items that may develop into two directions. For example, the number of countries using the tool may not always diminish but also increase, or an external penetration test may not be repeated as required. It may increase scaling if those subindicators that do require a regular renewal or update be explicitly highlighted to facilitate monitoring of the status. Another difficulty appeared with the subindicator for global utility, "Source Code Accessibility," as it was not entirely clear what "new modules" and "functionality" meant in the context of this model: In contrast to modular systems, some mHealth apps are built specifically to deliver a ready-to-go solution for a specific task, and they are defined by external standards that govern how the internal processes of the end users work. In such a situation, the requirement for facilitating options 
for developing new modules and functionalities without prematurely forking the code may not be applicable.

For the time being, the GGMM serves as a self-assessment system. In that, the authors can confirm that in the case of SORMAS, it has dramatically guided the prioritization and acceleration of its development. It appears to be the main objective of the model. On the other hand, self-assessment also allows for a certain degree of subjectivity or bias [19]. To reduce this risk, we contacted 2 external experts who were not involved in the development and deployment of SORMAS but were instead instrumental in the development of the GGMM. Through this we aimed to reduce conflicts of interest and maximize the expertise on SORMAS as well as on the interpretation of the GGMM. We believe that inviting independent external experts in reviewing this assessment may be a model for other projects and tools to apply the GGMM assessment. We do not entirely recommend an external assessment, as practiced in many accreditation procedures, because it carries the risk of creating a business that will only but draw resources needed for the actual development of the tools.

\section{Conclusions}

To our knowledge, SORMAS is the first electronic health tool for disease surveillance, and also the first outbreak response management tool, that has reached the full score (100\%) of the GGMM. The GGMM is clear in most of its definitions and is easy to apply for self-assessment, although some indicators require more resources for completion than others. Some conceptual modifications would allow for further improvements to the system. Nevertheless, it already has a supportive effect on developing software toward global goods maturity.

\section{Acknowledgments}

The authors would like to thank BMZ, Federal Ministry of Economic Cooperation and Development; European Union, via Deutsche Gesellschaft für Internationale Zusammenarbeit, Deutschen Zentrum für Infektionsforschung for funding the development of SORMAS since 2015.

\section{Authors' Contributions}

DT, BS, and GK searched, selected, and extracted data based on the criteria. DT conceptualized the first draft and GK analyzed and interpreted the results of the data. DT, GK, BS, CA, and JD reviewed the GGMM criteria for SORMAS development. MW and MS contributed to the development of SORMAS software. CL and CF represented Digital Square and the initiative that convened the initial creation of the GGMM version 1.0 and assisted in the SORMAS GGMM assessment. GK initiated the study approach and supervised all steps of the study. All authors revised and contributed to the final manuscript.

\section{Conflicts of Interest}

None declared.

\section{References}

1. Tom-Aba D, Nguku PM, Arinze CC, Krause G. Assessing the concepts and designs of 58 mobile apps for the management of the 2014-2015 West Africa Ebola outbreak: systematic review. JMIR Public Health Surveill 2018 Oct 29;4(4):e68 [FREE Full text] [doi: 10.2196/publichealth.9015] [Medline: 30373727]

2. AbouZahr C, Boerma T. Health information systems: the foundations of public health. Bull World Health Organ 2005 Aug;83(8):578-583 [FREE Full text] [Medline: 16184276]

3. Free C, Phillips G, Watson L, Galli L, Felix L, Edwards P, et al. The effectiveness of mobile-health technologies to improve health care service delivery processes: a systematic review and meta-analysis. PLoS Med 2013;10(1):e1001363 [FREE Full text] [doi: 10.1371/journal.pmed.1001363] [Medline: 23458994]

4. Qiang CZ, Yamamichi M, Hausman V, Altman D. World Bank. Washington, DC: World Bank; 2011 Dec. Mobile Applications for the Health Sector URL: http://siteresources.worldbank.org/ INFORMATIONANDCOMMUNICATIONANDTECHNOLOGIES/Resources/mHealth report.pdf [accessed 2020-03-03]

5. Labrique AB, Wadhwani C, Williams KA, Lamptey $P$, Hesp C, Luk R, et al. Best practices in scaling digital health in low and middle income countries. Global Health 2018 Nov 3;14(1):103 [FREE Full text] [doi: 10.1186/s12992-018-0424-z] [Medline: $\underline{\text { 30390686] }}$

6. Digital Impact Alliance (DIAL). 2017. URL: https://digitalimpactalliance.org/ [accessed 2019-10-31]

7. Health Data Collaborative. What We Do: Better Data. Better Health URL: https://www.healthdatacollaborative.org/ what-we-do/ [accessed 2017-10-20]

8. PATH. 2017 Sep 28. Digital Health: New Global Initiative Will Connect the World for Better Health Through Digital Technology URL: http://www.path.org/news/press-room/846/ [accessed 2019-10-31]

9. Fähnrich C, Denecke K, Adeoye OO, Benzler J, Claus H, Kirchner G, et al. Surveillance and Outbreak Response Management System (SORMAS) to support the control of the Ebola virus disease outbreak in West Africa. Euro Surveill 2015 Mar 26;20(12):pii: 21071 [FREE Full text] [doi: 10.2807/1560-7917.es2015.20.12.21071] [Medline: 25846493]

10. Perscheid C, Benzler J, Hermann C, Janke M, Moyer D, Laedtke T, et al. Ebola outbreak containment: real-time task and resource coordination with SORMAS. Front ICT 2018;5:7. [doi: 10.3389/fict.2018.00007] 
11. Adeoye O, Tom-Aba D, Ameh C, Ojo O, Ilori E, Gidado S, et al. Implementing Surveillance and Outbreak Response Management and Analysis System (SORMAS) for public health in west Africa- lessons learnt and future direction. Int $\mathbf{J}$ Trop Dis Health 2017;22(2):1-17. [doi: 10.9734/ijtdh/2017/31584]

12. Digital Square. 2019 May. Global Goods Guidebook URL: https://digitalsquare.org/global-goods-guidebook [accessed 1999-11-30]

13. Digital Square Wiki. What are Global Goods URL: https://wiki.digitalsquare.io/index.php/What are Global Goods [accessed 1999-11-30]

14. Yinka-Ogunleye A, Aruna O, Dalhat M, Ogoina D, McCollum A, Disu Y, CDC Monkeypox Outbreak Team. Outbreak of human monkeypox in Nigeria in 2017-18: a clinical and epidemiological report. Lancet Infect Dis 2019 Aug;19(8):872-879. [doi: 10.1016/S1473-3099(19)30294-4] [Medline: 31285143]

15. Silenou BC, Tom-Aba D, Adeoye O, Arinze CC, Oyiri F, Suleman AK, et al. Use of surveillance outbreak response management and analysis system for human monkeypox outbreak, Nigeria, 2017-2019. Emerg Infect Dis 2020 Feb;26(2):345-349 [FREE Full text] [doi: 10.3201/eid2602.191139] [Medline: 31961314]

16. Tom-Aba D, Toikkanen SE, Glöckner S, Adeoye O, Mall S, Fähnrich C, et al. User Evaluation Indicates High Quality of the Surveillance Outbreak Response Management and Analysis System (SORMAS) After Field Deployment in Nigeria in 2015 and 2018. Stud Health Technol Inform 2018;253:233-237. [Medline: 30147081]

17. District Health Information System. Digital Square. 2019. Global Goods Maturity Assessment URL: https://applications. digitalsquare.io/notice-c/concept-note/76 [accessed 2020-02-20]

18. Wing O, Huang JW. A computation model of parallel solution of linear equations. IEEE Trans Comput 1980;C-29(7):632-638. [doi: $10.1109 /$ tc. 1980.1675634$]$

19. Bernheim JL, Theuns P, Mazaheri M, Hofmans J, Fliege H, Rose M. The Potential of Anamnestic Comparative Self-Assessment (ACSA) to Reduce Bias in the Measurement of Subjective Well-Being. J Happiness Stud 2006;7(2):227-250. [doi: $10.1007 / \mathrm{s} 10902-005-4755-0]$

\author{
Abbreviations \\ GGMM: global good maturity model \\ LGA: local government area \\ mHealth: mobile health \\ SORMAS: Surveillance and Outbreak Response Management and Analysis System
}

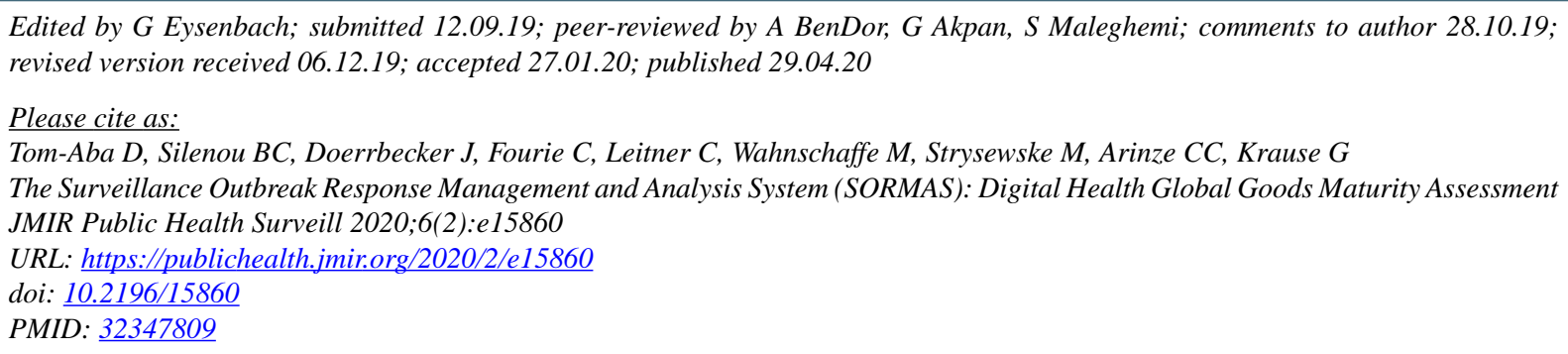

CDaniel Tom-Aba, Bernard Chawo Silenou, Juliane Doerrbecker, Carl Fourie, Carl Leitner, Martin Wahnschaffe, Maté Strysewske, Chinedu Chukwujekwu Arinze, Gerard Krause. Originally published in JMIR Public Health and Surveillance (http://publichealth.jmir.org), 29.04.2020. This is an open-access article distributed under the terms of the Creative Commons Attribution License (https://creativecommons.org/licenses/by/4.0/), which permits unrestricted use, distribution, and reproduction in any medium, provided the original work, first published in JMIR Public Health and Surveillance, is properly cited. The complete bibliographic information, a link to the original publication on http://publichealth.jmir.org, as well as this copyright and license information must be included. 